\title{
FEEDBACK
}

\section{Determinants of Corporate Performance: A Comment}

ONE CAN perhaps summarize Prof. Eilon's essay on the determinants of corporate performance [1] as "Usually, everything matters, but nothing matters much." This summary immediately suggests the stochastic growth perspective on the issue of firm performance.

The stochastic growth approach models the observed growth and decline firms as the outcome of a large number of factors, none of which is dominant and many of which originate in the environment. This approach is due to the work of Gibrat [3], who states that all firms draw their growth rates over a period from the same distribution (i.e. growth is independent of starting size or previous growth).

Although Gibrat's Law may seem extreme, it may not be too far off the mark [4]. I am aware of over forty studies testing this Law for all of the largest firms in a single country, or firms in a number of industries in various countries including Austria, Australia, Germany, Mexico, South Africa, Sweden, the United Kingdom and the United States. I have applied the approach to the world's largest banks [6].

In general, the evidence on the independence of growth and firm size is ambiguous. Smaller firms growing faster than larger ones, the opposite, or neither having an advantage are equally common results. What is more consistent is the finding that the variability of growth rates declines with firm size.

This suggests a view of the firm as a portfolio of projects, defined by the sale of products in given geographic areas. Small firms have few projects and large firms many. R\&D would make a more visible impact in the case of small firms, where a lucky discovery could yield several years of growth above the average. In large firms the impact of any particular project disappears in the noise. Better management in these firms is analogous to better management of portfolios of securities, where the finance literature suggests above average performance is very hard to detect statistically

In competitive environments, managers are in a Prisoners' Dilemma. The reward for working hard is average performance. It is the penalty for not working hard that provides the motivation. Klein refers to this as the "invisible foot" [5].
The descriptive success of the stochastic growth approach leads me to infer that search for $a$ determinant of corporate growth, or even for stable indicators of the relative importance of different factors, is pointless. Nature is not very informative; there are too many factors and not enough data points. The passage of time only brings new factors. Furthermore, there is no reason to believe that the processes involved are stable. The seminal work of Emery and Trist on the causal textures of organizational environments is relevant [2]. In a turbulent environment, causal links are undetectable.

The lesson for managers is that many things are important but nothing appears to be the answer. Managers will continue to have to worry about a great many things, and frequently have to make decisions on the basis of their beliefs and intuition. The contribution of researchers is then to examine experience to improve the checklists that managers could use to ensure that they do not unintentionally omit factors from consideration before making decisions.

\section{REFERENCES}

1. Eilon $S(1985)$ The determinants of corporate performance. Omega 13 (6), 479-486.

2. Emery FE and Trist EL (1965) The causal textures of organizational environments. Human Relations 18 (1), 21-32.

3. Gibrat R (1931) Les inegalités économiques. Recueil Sirey, Paris. Extract available as "On economic inequalities," International Economic Papers (1957) Macmillan, New York.

4. Ijiri Y and Simon HA (1977) Skew Distributions and the Sizes of Business Firms. North-Holland, Amsterdam, New York and Oxford.

5. Klein BH (1977) Dynamic Economics. Harvard University, Cambridge, MA.

6. Tschoegl AE (1983) Size, growth, and transnationality among the world's largest banks. $\mathrm{Jl}$. Busin. 56 (2), 187-201

Adrian E Tschoegl (February 1986)
Assistant Professor of International Business

Graduate School of Business Administration

The University of Michigan

Ann Arbor

MI 48109

USA 